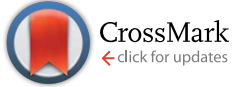

Cite this: RSC Adv., 2015, 5, 31166

Received 15th February 2015 Accepted 25th March 2015

DOI: $10.1039 / c 5 r a 02940 f$

www.rsc.org/advances

\title{
Determination of the formation and range of stability of the SEI on glassy carbon by local electrochemistry
}

\author{
Giorgia Zampardi, ${ }^{\text {ab }}$ Fabio La Mantia*b and Wolfgang Schuhmann*a
}

\begin{abstract}
The solid electrolyte interphase (SEI) is an electronic insulating and ionic conducting layer that is of main importance in lithium-ions batteries, since it critically affects the final performance of the battery system. The formation of this electronic insulating layer was determined in operando on a glassy carbon electrode by means of a microelectrode positioned in close proximity to its surface using scanning electrochemical microscopy (SECM). Glassy carbon was chosen as an ideal model system for carbonaceous materials, since it forms a SEI similar in composition to the one on graphite but concomitantly shows negligible intercalation of lithium ions. Moreover, the stability of the SEI was analysed depending on different potential ranges and the role of the cations on the insulating character of the SEI was investigated.
\end{abstract}

\section{Introduction}

The formation of the solid electrolyte interphase (SEI) is one of the main sources of irreversible charge loss during the operation of lithium-ion batteries based on graphite and silicon negative electrodes. ${ }^{\mathbf{1} 2}$ The SEI layer is formed during the first cycle from the irreversible decomposition products of the electrolyte components. ${ }^{2}$ Its main characteristic is to be an electronic insulator and an ionic conductor for lithium ions. A stable SEI is absolutely necessary for a long cycle life, reduced safety risks, and high coulombic efficiency of the battery. ${ }^{1,3}$

Since the properties of the SEI affect critically the final performance of a lithium-ion battery, a variety of both ex situ and in situ techniques were developed. Frequently used ex situ techniques are X-ray photoelectron spectroscopy (XPS), ${ }^{4,5}$ scanning electron microscopy (SEM), ${ }^{6}$ and transmission electron spectroscopy (TEM). ${ }^{7}$ However, in situ techniques are of main importance because they allow the analysis of the SEI in its native environment. In this way, any possible degradation of this layer is avoided which may be potentially caused by the transfer of the material into an analysis chamber or due to the environment in the analysis chamber itself (such as ultra-high vacuum). For this reason Fourier transform infrared spectroscopy (FTIR), ${ }^{3}$ Raman spectroscopy, ${ }^{\mathbf{8} 9}$ differential electrochemical mass spectrometry (DEMS $)^{10-12}$ are often employed hyphenated or together with more

\footnotetext{
${ }^{a}$ Analytical Chemistry-Center for Electrochemical Sciences (CES), Ruhr-Universität Bochum, Universitätsstr. 150, D-44780 Bochum, Germany. E-mail: wolfgang. schuhmann@rub.de

${ }^{b}$ Semiconductor and Energy Conversion, Center for Electrochemical Sciences (CES), Ruhr-Universität Bochum, Universitätsstr. 150, D-44780 Bochum, Germany. E-mail: fabio.lamantia@rub.de
}

conventional electrochemical techniques such as cyclic voltammetry, galvanostatic cycling and electrochemical impedance spectroscopy (EIS). ${ }^{\mathbf{1 3 , 1 4}}$

For graphite, exhibiting an operation range between 0.3 and $0.005 \mathrm{~V}$ vs. $\mathrm{Li} / \mathrm{Li}^{+}$, a stable SEI, which forms before the first intercalation of lithium, is of high importance. Even though the formation and properties of the SEI have been studied intensively, a clear and comprehensive understanding of this layer was still not achieved. ${ }^{2}$

Scanning electrochemical microscopy (SECM) in its feedback mode of operation was recently suggested as an in operando technique to determine on the one hand the potential of the SEI formation and on the other hand to in-depth evaluate the electronic insulating properties of this layer. It was shown ${ }^{15}$ that SECM can be advantageously employed to follow the formation of an insulating layer on the surface of a chosen battery material by recording the current at a microelectrode positioned near the surface of the sample. The current at the microelectrode is modulated by the changes in the kinetics of the electron transfer reaction between a free diffusing redox species and the sample surface. While other techniques provide information on the nature of the compounds forming the SEI, ${ }^{\mathbf{4}, 16}$ feedback mode SECM allows evaluating electronic insulating properties of the SEI, which is of essential importance for a deep insight into the operation of the battery.

Due to its stability ferrocene/ferrocenium $\left(\mathrm{Fc} / \mathrm{Fc}^{+}\right)$was chosen as free diffusing redox species for the feedback experiments. In order to detect in operando SEI formation, back reduction of ferrocenium $\left(\mathrm{Fc}^{+}\right)$, generated at the positioned SECM tip, was followed at the potentiodynamically cycled glassy carbon surface. The key factor for SEI detection is to achieve a drastic decrease of the rate of $\mathrm{Fc}^{+}$back reduction at the SEI 
covered sample surface. It was shown by Newman et al. ${ }^{17}$ that the back reduction of $\mathrm{Fc}^{+}$is efficiently blocked when the SEI is present on the surface of a highly pyrolytic graphite electrode. Moreover, Kaymaksiz et al. ${ }^{18}$ recently studied the influence of the Fc and the 2,5-di-tert-butyl-1,4-dimethoxybenzene (DTMBDMB) as redox shuttle additives on the SEI formed on glassy carbon electrodes. In contrast to ferrocene, DTMBDMB showed a substantial kinetics for its reduction even at a SEI covered glassy carbon surface. Thus, the $\mathrm{Fc} / \mathrm{Fc}^{+}$couple is supposed to be more suitable for the in operando evaluation of SEI formation and stability.

Here, we follow the formation and stability of the SEI on glassy carbon electrodes by means of feedback mode SECM. Glassy carbon was chosen as a model carbon surface, since on the one hand it forms a SEI on its surface with similar characteristics than the one formed on graphite while on the other hand it shows negligible intercalation of lithium ions. ${ }^{19}$ Hence, it is possible to separate the impact of $\mathrm{Li}^{+}$intercalation and SEI formation on the feedback current recorded at the microelectrode. ${ }^{20}$ The effect of the polarization potential range and of the presence of different cations, namely tetrabutylammonium or sodium ions, on the stability and electronic insulating properties of the SEI was evaluated as well.

\section{Experimental}

\subsection{SECM set-up}

The SECM set-up was integrated inside a glove box (Jacomex) filled with argon in order to exclude any traces of $\mathrm{O}_{2}$ and $\mathrm{H}_{2} \mathrm{O}$ (below 1 ppm) during all the experiments. For this reason a customized commercial SECM (Sensolytics) was used. Because of the dry atmosphere inside the glovebox, special positioning motors (OWIS) were employed and the bi-potentiostat (Jaissle PG-100) was placed outside the glovebox. Bi-potentiostat, AD/ DA converter (Measurement Computing Corporation), piezo controller (Physik Instrumente) and computer (outside the glove box) were connected with the SECM set-up (inside the glove box) through BNC connectors. The SECM was controlled by an in-house developed software. ${ }^{15,20}$

\subsection{SECM measurements}

For the SECM measurements a $25 \mu \mathrm{m}$ diameter platinum microelectrode was positioned at $20 \mu \mathrm{m}$ distance from the sample surface. The microelectrode was prepared using a $25 \mu \mathrm{m}$ diameter Pt wire (Goodfellow) sealed in a glass capillary. Mechanical polishing of the glass capillary was performed using a special home-made apparatus. ${ }^{21}$ Ferrocene (98\%, SigmaAldrich) with a concentration of $20 \mathrm{mM}$ was selected as redox species in solution. The supporting electrolytes used for different experiments were: $1 \mathrm{M}$ lithium perchlorate (battery grade, dry, 99.99\% Sigma-Aldrich), $1 \mathrm{M}$ tetrabutylammonium perchlorate ( $\geq 99.0 \%$ Sigma-Aldrich), $1 \mathrm{M}$ sodium perchlorate ( $\geq 98.0 \%$ Sigma-Aldrich).

All electrolytes were based on ethylene carbonate (EC) (anhydrous 99\%, Sigma-Aldrich) and diethyl carbonate (DEC) (anhydrous 99.7\%, Sigma-Aldrich), 1:1 weight ratio as solvents. All potential values are referred to a reference electrode composed of metallic lithium immersed in $1 \mathrm{M} \mathrm{LiClO}_{4}$ EC : PC solution (PC, propylene carbonate, 99\%, SigmaAldrich), separated from the main body of the cell by a ceramic frit. For experiments in absence of lithium ions in solution, a double junction containing $1 \mathrm{M}$ tetrabutylammonium perchlorate or $1 \mathrm{M}$ sodium perchlorate was used. As counter electrode a cylindrical titanium mesh (Alfa Aesar) covered with $\mathrm{TiS}_{2}$ (99\%, Sigma-Aldrich) or electrochemically grown poly(3,4-ethylenedioxythiophene) was used.

All measurements were carried out in a specifically developed four electrode electrochemical cell. ${ }^{20}$ The bi-potentiostat was used to record the current at the SECM tip (working electrode 2) while polarizing the glassy carbon sample (working electrode 1). In order to avoid evaporation of solvents, a specifically designed lid was employed during all measurements. The exposed area of the glassy carbon electrodes (HTW - Hochtemperatur-Werkstoffe) was $0.125 \mathrm{~cm}^{2}$.

A cyclic voltammogram at the microelectrode was performed before and after each experiment to verify the quality of the recorded data. No electrode fouling was observed for all performed experiments. The current with the microelectrode positioned in the bulk of the electrolyte shifted less than $2 \%$ for all cases. The current at the microelectrode was always normalized by the current at far distance from the surface:

$$
\frac{I_{\mathrm{T}}}{I_{\mathrm{bulk}}}
$$

where $I_{\mathrm{T}}$ is the current at the microelectrode and $I_{\text {bulk }}$ the mass transport limited current in the bulk of the electrolytic solution.

\section{Results and discussion}

\subsection{Influence of the applied potential on the SEI stability}

SECM experiments were performed using the feedback mode. When a microelectrode approaches the sample surface, its current, $I_{\mathrm{T}}$, increases if the surface of the substrate is electronically conductive and reactive, while it decreases if the surface of the substrate is electronically insulating or inert. ${ }^{22}$ At constant tip-to-sample distance, when a potential more cathodic than the formal potential of the redox couple is applied to the sample, the feedback current recorded at the microelectrode increases until it reaches a limiting value. On the other side, when the potential applied to the sample is sufficiently cathodic to form the SEI, the feedback current recorded at the microelectrode decreases due to the electronically insulating nature of this protective layer, as reported previously. ${ }^{15,20}$

After approaching the SECM tip towards the surface of the glassy carbon, the microelectrode was kept at a constant $z$ distance and at a constant potential, namely $20 \mu \mathrm{m}$ and $3.6 \mathrm{~V} v s$. $\mathrm{Li} / \mathrm{Li}^{+}$, respectively. Then a cyclic voltammogram was recorded at the glassy carbon electrode and the evolution of the feedback current at the microelectrode was followed. Starting from freshly polished glassy carbon electrodes, different potential ranges were applied during voltammetry: (i) from $3 \mathrm{~V}$ to $1 \mathrm{~V} v s$. $\mathrm{Li} / \mathrm{Li}^{+}$; (ii) from $1 \mathrm{~V}$ to $0.005 \mathrm{~V} v$ s. $\mathrm{Li} / \mathrm{Li}^{+}$; and (iii) from $3 \mathrm{~V}$ to 0.005 $\mathrm{V}$ vs. $\mathrm{Li} / \mathrm{Li}^{+}$. 
Due to the very low cathodic potentials which had to be applied to the glassy carbon surface, a cyclic voltammogram in a potential range between $3 \mathrm{~V}$ and $0.005 \mathrm{~V} v s$. $\mathrm{Li}_{/} \mathrm{Li}^{+}$was recorded in presence and in absence of Fc to evaluate Fc stability at these potentials (Fig. 1).

The overlapping voltammograms suggest that Fc does not undergo any further reduction confirming its exceptional stability in the used electrolyte solution.

Fig. 2a shows the cyclic voltammogram of the glassy carbon electrode in a potential range from $3 \mathrm{~V}$ to $1 \mathrm{~V} v s$. $\mathrm{Li} / \mathrm{Li}^{+}$at a scan rate of $0.1 \mathrm{mV} \mathrm{s}^{-1}$ and the corresponding normalized feedback current at the microelectrode positioned at a distance of $20 \mu \mathrm{m}$ above the glassy carbon surface.

By polarizing cathodically, the normalized feedback current slightly increases due to the increase of the driving force for the back reduction of the $\mathrm{Fc}^{+}$at the glassy carbon surface. However, no sudden decrease of the tip current is observed, confirming that in this potential range no SEI is formed in agreement with the literature. ${ }^{3}$ This can be further proved by $z$-approach curves of the microelectrode towards the sample surface before and after recording the cyclic voltammogram (Fig. 2b). The normalized feedback current remains above 1 after the substrate is cycled down to $1 \mathrm{~V} v s$. $\mathrm{Li} / \mathrm{Li}^{+}$.

On the same sample two polarization cycles between $1 \mathrm{~V}$ and $0.005 \mathrm{~V} v s . \mathrm{Li} / \mathrm{Li}^{+}$were then performed at a scan rate of $0.1 \mathrm{mV} \mathrm{s}^{-1}$, as shown in Fig. $3 \mathrm{a}$ and $\mathrm{b}$. In the first cycle (Fig. 3a) the normalized feedback current starts decreasing when the polarization potential reaches $0.8 \mathrm{~V} v s$. $\mathrm{Li} / \mathrm{Li}^{+}$. This suggests that an insulating layer starts forming around this potential, in agreement with earlier in situ DEMS studies. ${ }^{11}$ During DEMS experiments the evolution of ethylene takes place in the first cycle at a potential of around $0.8 \mathrm{Vvs} . \mathrm{Li} / \mathrm{Li}^{+}$. However, the same authors observed that simultaneously $\mathrm{CO}_{2}$ is evolved during the reduction of the solvent in the first cycle, at a potential of $1 \mathrm{~V} v s$. $\mathrm{Li} / \mathrm{Li}^{+}$. Possibly, the products of the reduction of EC and DEC at this potential, which are $\mathrm{CO}_{2}$ and radical ions, are not able to form an electronically insulating layer, while when the reduction of the solvent produces ethylene gas and carbonate, the latter precipitates under formation of $\mathrm{Li}_{2} \mathrm{CO}_{3}$ which is electronically insulating. ${ }^{11}$

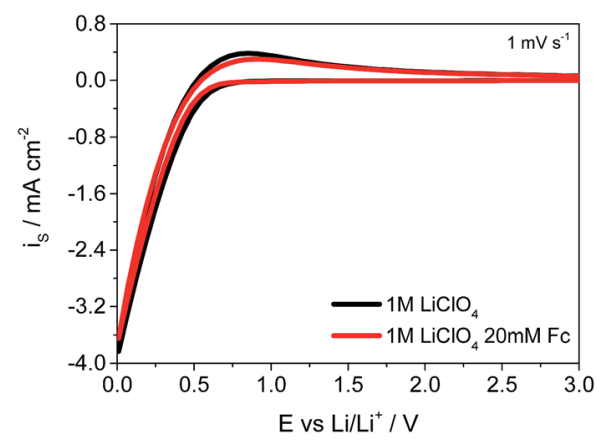

Fig. 1 Cyclic voltammogram of a glassy carbon electrode in $1 \mathrm{M}$ $\mathrm{LiClO}_{4}$ in EC : DEC (1:1\%wt) at a scan rate of $1 \mathrm{mV} \mathrm{s}^{-1}$, in presence and in absence of ferrocene in the electrolyte.
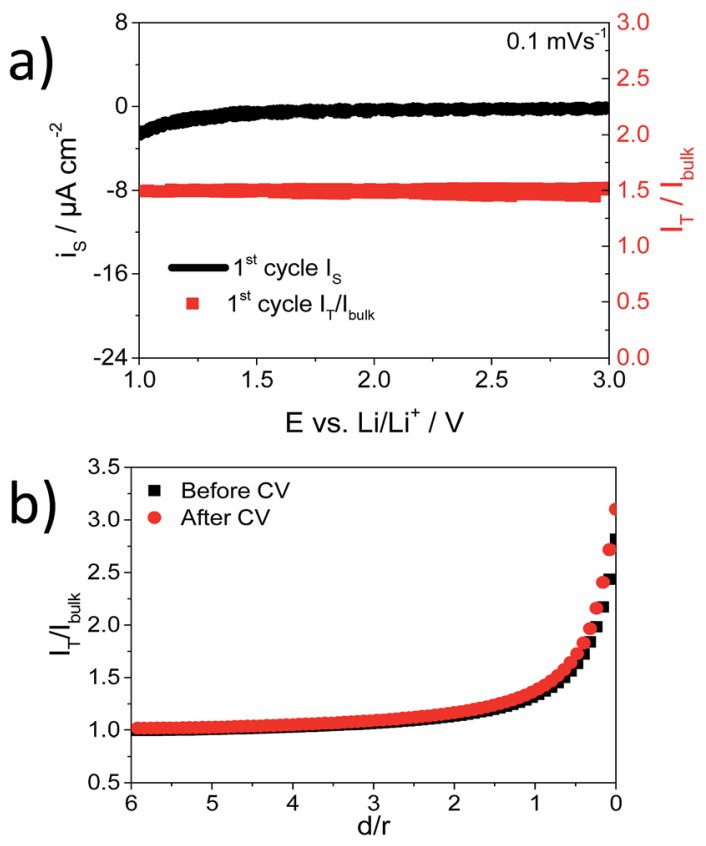

Fig. 2 (a) Cyclic voltammogram of a glassy carbon electrode in $1 \mathrm{M}$ $\mathrm{LiClO}_{4}, 20 \mathrm{mM} \mathrm{FC}$ in EC : DEC (1:1\%wt) at a scan rate of $0.1 \mathrm{mV} \mathrm{s}^{-1}$, first cycle, and the corresponding feedback current at the microelectrode polarised to $3.6 \mathrm{~V}$ vs. $\mathrm{Li} / \mathrm{Li}^{+}$. (b) $z$-approach curves of the microelectrode ( $r$ : radius of the microelectrode, $12.5 \mu \mathrm{m}$; $d$ : tip-tosample distance) to the sample surface, before and after the cyclic voltammetry was performed at the glassy carbon electrode. Applied potential at the microelectrode: $3.6 \mathrm{~V}$ vs. $\mathrm{Li} / \mathrm{Li}^{+}$. Applied potential at the glassy carbon electrode for the $z$-approach curve: 1 V vs. Li/Li+
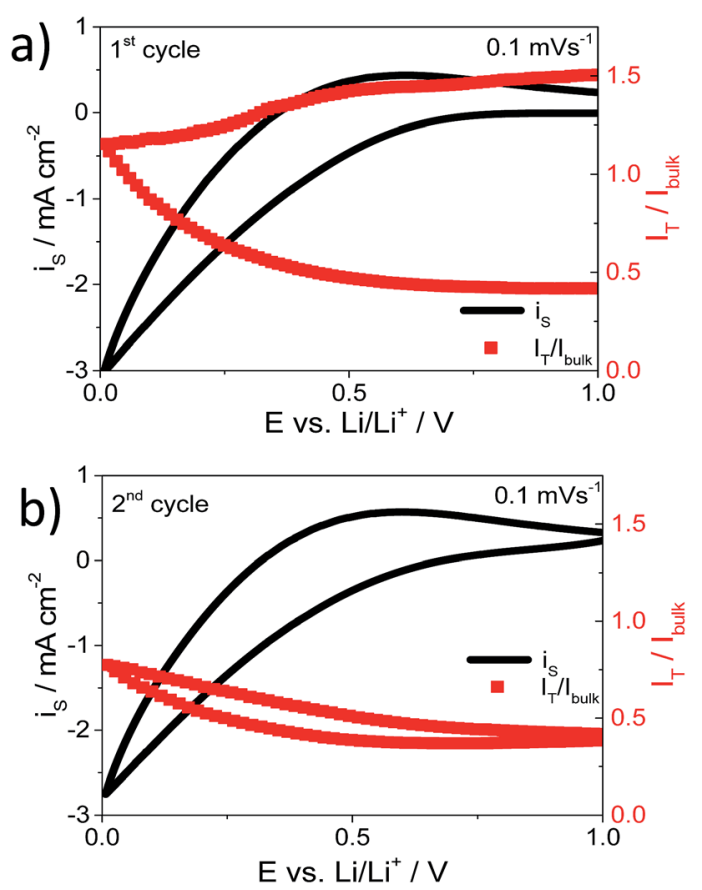

Fig. 3 Cyclic voltammogram of a glassy carbon electrode in $1 \mathrm{M}$ $\mathrm{LiClO}_{4}$ containing $20 \mathrm{mM} \mathrm{FC} \mathrm{in} \mathrm{EC} \mathrm{:} \mathrm{DEC}(1: 1 \% \mathrm{wt})$ at a scan rate of 0.1 $\mathrm{mV} \mathrm{s}^{-1}$. (a) First cycle; (b) second cycle, and the corresponding feedback current at the microelectrode polarised to $3.6 \mathrm{~V} v \mathrm{~s}$. Li/ $\mathrm{Li}^{+}$. 
Thus, it can be deduced that the radical ion is not able to form a proper insulating layer, differently than reported in. ${ }^{23}$ In the second cycle (Fig. 3b), the normalized feedback current remains lower than 1 , confirming the irreversible character of the SEI formation process.

The same experiment was repeated at a freshly polished glassy carbon electrode, however, this time in the potential range from $3 \mathrm{~V}$ to $0.005 \mathrm{~V} v$ s. $\mathrm{Li} / \mathrm{Li}^{+}$(Fig. $4 \mathrm{a}$ and b). In the first cycle of the voltammogram (Fig. 4a), the potential at which the feedback current starts decreasing is $0.8 \mathrm{~V} v s$. $\mathrm{Li} / \mathrm{Li}^{+}$, consistent with the previous experiment. During the following anodic halfscan the feedback current increases by $8.7 \%$ when the potential applied to the glassy carbon surface is changed from $1 \mathrm{~V}$ to $3 \mathrm{~V}$ $v s$. $\mathrm{Li} / \mathrm{Li}^{+}$. We expected a slight decrease in the feedback current due to the decreasing driving force for $\mathrm{Fc}^{+}$back reduction. Therefore, the increase in the feedback current during the anodic sweep could be attributed to a partial degradative oxidation of the SEI layer. This is in agreement with previous observations from XPS analysis on the change in composition and thickness of the SEI reported by Bryngelsson et al. ${ }^{24}$ However, as observed in Fig. 4b, the overall insulating character of the SEI does not change drastically. Therefore, in contrast to the findings reported in ref. 24, cycling the electrode at potentials above $1 \mathrm{~V}$ vs. $\mathrm{Li} / \mathrm{Li}^{+}$was confirmed to not affect substantially the electronic insulating characteristic of the SEI layer. In order to compare $z$-approach curves performed after the different applied potential ranges, it was necessary to eliminate differences in the tilt between microelectrode and substrate which are specific of the single experiments. Thus, different
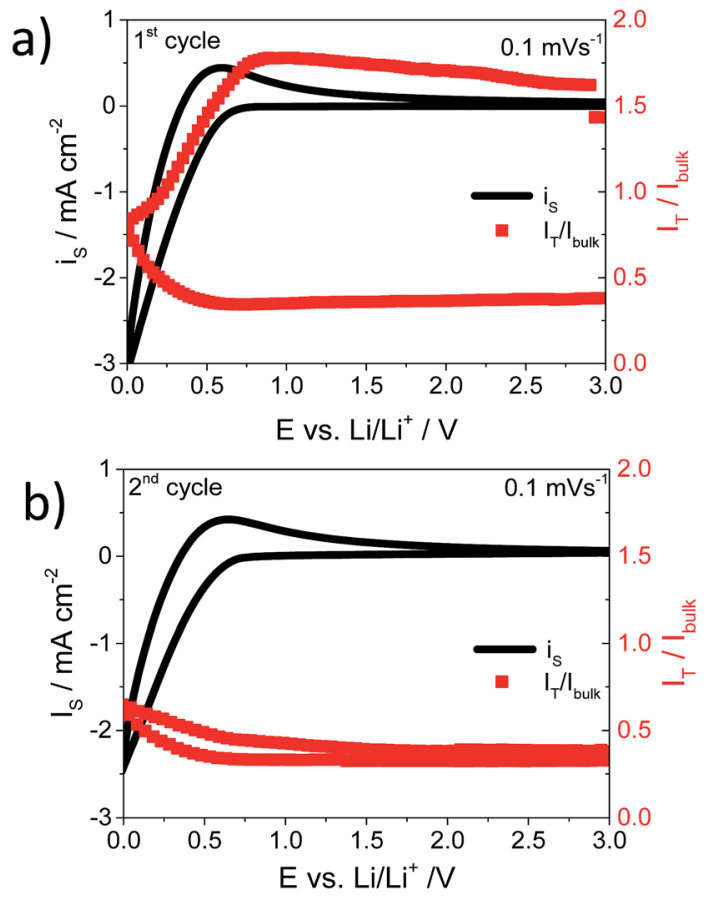

Fig. 4 Cyclic voltammogram of a glassy carbon electrode in $1 \mathrm{M}$ $\mathrm{LiClO}_{4}$ containing $20 \mathrm{mM} \mathrm{FC}$ in EC : DEC (1: $\left.1 \% \mathrm{wt}\right)$ at a scan rate of 0.1 $\mathrm{mV} \mathrm{s}^{-1}$. (a) First cycle, (b) second cycle, and the corresponding feedback current at the microelectrode polarised at $3.6 \mathrm{~V} v \mathrm{~s}$. Li/ $\mathrm{Li}^{+}$. polarization ranges were applied consecutively on a single glassy carbon electrode, as shown in Fig. 5.

A $z$-approach curve has been performed between each polarization set, maintaining the potential of the glassy carbon equal to $1 \mathrm{~V} v s$. $\mathrm{Li} / \mathrm{Li}^{+}$. At first the substrate was polarized between $3 \mathrm{~V}$ and $1 \mathrm{~V} v$ s. $\mathrm{Li} / \mathrm{Li}^{+}$(Fig. 5a, set 1), subsequently the potential was swept between $1 \mathrm{~V}$ and $0.005 \mathrm{~V} v s$. $\mathrm{Li} / \mathrm{Li}^{+}$for two cycles (Fig. 5b, set 2). Thereafter, the same sample was polarised to $3 \mathrm{~V}$ and the potential was swept down to $0.005 \mathrm{~V} v s . \mathrm{Li} / \mathrm{Li}^{+}$ (Fig. 5c, set 3) for two cycles. All potential sweeps were performed at $0.1 \mathrm{mV} \mathrm{s}^{-1}$ and the voltammograms were stopped at a potential of $1 \mathrm{~V} v s$. $\mathrm{Li} / \mathrm{Li}^{+}$.

In the $z$-approach curves recorded before and after set 1 (Fig. 5d), the normalized feedback current remained higher than unity in agreement to the fact that no SEI was formed above $1 \mathrm{~V} v s$. $\mathrm{Li} / \mathrm{Li}^{+}$. The $z$-approach curves recorded after set 2 and 3 (Fig. 5e and f, respectively) show a normalized feedback current lower than 1 in both cases. At the coordinates of closest approach to the glassy carbon surface, the normalized feedback current was only 0.03 after set 2 . After set 3 , the normalized feedback current was 0.035 . This further proved that even when the once formed SEI is exposed to high polarization potentials, its insulating character is only slightly degraded.

\subsection{Influence of the cation on the insulating character of the SEI}

In order to investigate the role of cations on the electronic properties of the formed SEI, similar experiments were performed in different solutions containing $\mathrm{TBAClO}_{4}$ or $\mathrm{NaClO}_{4}$ as background electrolyte. No lithium ions were present in solution, and this was further ensured by the use of a double junction for the $\mathrm{Li} / \mathrm{Li}^{+}$reference electrode. The polarization range of two freshly cleaned glassy carbon electrodes was chosen to be between $1 \mathrm{~V}$ and $0.005 \mathrm{~V} v s . \mathrm{Li} / \mathrm{Li}^{+}$in the case of the solution containing the tetrabutylammonium salt. For the sodium salt, a potential range between $1 \mathrm{~V}$ and $0.35 \mathrm{~V} v s . \mathrm{Li} / \mathrm{Li}^{+}$ was applied in order to avoid deposition of metallic sodium on the glassy carbon electrode. When the microelectrode was held in close proximity of the surface of the glassy carbon electrode during the cyclic voltammogram, a severe fouling of the microelectrode was observed. This was attributed to a different mechanism of passivation of the glassy carbon surface in absence of lithium ions. The absence of lithium ions may lead to an extended polymerization of the decomposition products of the electrolyte, which could be the reason of the microelectrode fouling. Thus, in order to avoid any fouling of the microelectrode, it was kept in the bulk of the solution during the polarization of the glassy carbon electrode. Before and after the polarization of the glassy carbon electrode, $z$-approach curves were recorded (Fig. 6a and b). In both cases a normalized feedback current lower than unity was recorded upon approaching to the surface of the sample after cycling. This leads to the conclusion that also in absence of $\mathrm{Li}^{+}$ions an insulating layer is formed. This can be of importance if solutions containing $\mathrm{TBA}^{+}$cations are employed in electrochemical ultracapacitors. The previously reported ${ }^{25}$ low efficiency of such 

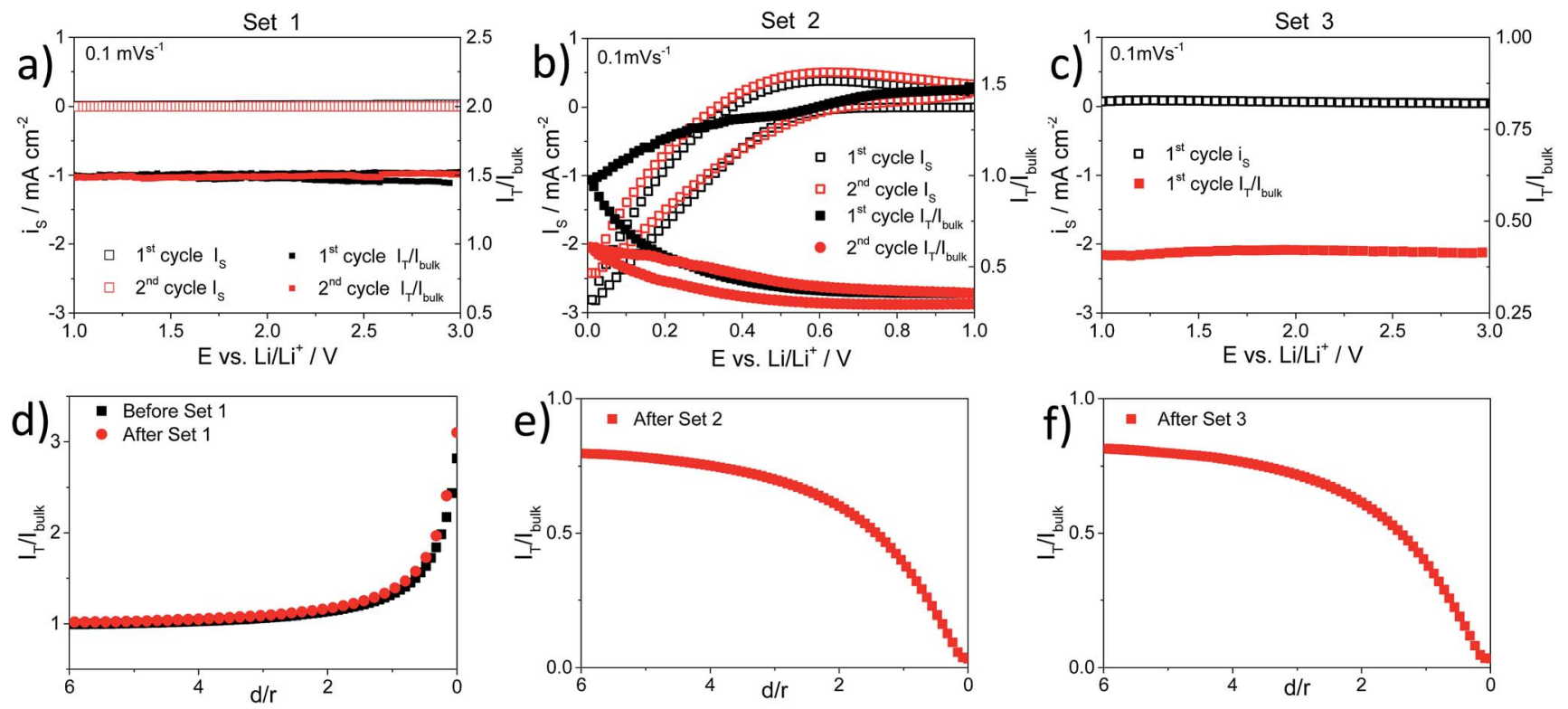

Fig. 5 Cyclic voltammogram of a glassy carbon electrode in $1 \mathrm{M} \mathrm{LiClO}_{4}$ containing $\left.20 \mathrm{mM} \mathrm{FC} \mathrm{in} \mathrm{EC:} \mathrm{DEC} \mathrm{(1:} 1 \% \mathrm{wt}\right)$ at a scan rate of $0.1 \mathrm{mV} \mathrm{s}{ }^{-1}$. (a) Set 1: applied potentials between $3 \mathrm{~V}$ and $1 \mathrm{~V}$ vs. $\mathrm{Li} / \mathrm{Li}^{+}$, three cycles; (b) set 2: applied potentials between $1 \mathrm{~V}$ and $0.005 \mathrm{~V}$ vs. Li/Li ${ }^{+}$, two cycles; (c) set 3: applied potentials between $3 \mathrm{~V}$ and $0.005 \mathrm{~V} v \mathrm{~s}$. Li/ $\mathrm{Li}^{+}$. For each set the corresponding feedback current at the microelectrode polarised to $3.6 \mathrm{~V} \mathrm{vs}$. $\mathrm{Li}^{\prime} \mathrm{Li}^{+}$is shown. (d), (e) and (f) $z$-approach curves of the microelectrode ( $r$ : radius of the microelectrode, $12.5 \mu \mathrm{m}$; $d$ : tip-to-sample distance) to the sample surface after set 1 , set 2 and set 3 respectively, before and after the cyclic voltammogram was performed at the glassy carbon electrode. Applied potential at the microelectrode was $3.6 \mathrm{~V} \mathrm{vs}$. Li/Li ${ }^{+}$. Applied potential at the glassy carbon electrode for each $z-$ approach curve was $1 \mathrm{~V}$ vs. $\mathrm{Li} / \mathrm{Li}^{+}$.
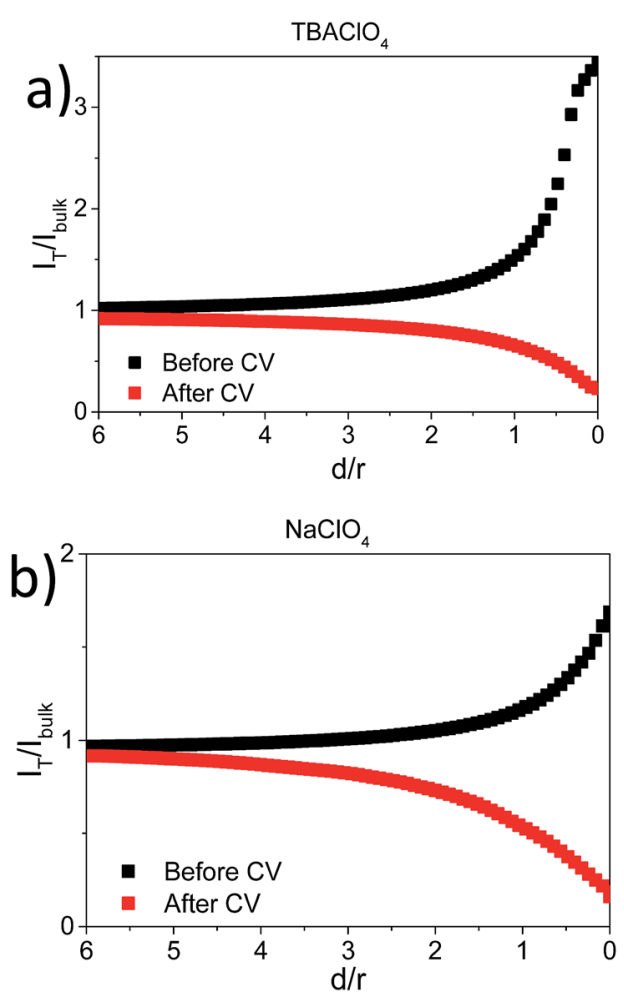

Fig. $6 z$-approach curves of the microelectrode $(r: 12.5 \mu \mathrm{m})$ to the sample surface in a solution containing (a) $\mathrm{TBAClO}_{4}$ and (b) $\mathrm{NaClO}_{4}$, respectively, before and after acyclic voltammogram was performed at the glassy carbon electrode. The applied potential at the microelectrode was $3.6 \mathrm{~V}$ vs. $\mathrm{Li} / \mathrm{Li}^{+}$. The applied potential at the glassy carbon electrode during the $z$-approach curve was $1 \mathrm{~V}$ vs. $\mathrm{Li} / \mathrm{Li}^{+}$. capacitors can actually be related to the formation of an electronic insulating layer due to the solvent decomposition.

Also in the case of sodium containing electrolytes an electronic insulating layer forms after polarization of the glassy carbon electrode. This can be regarded as an important finding for a possible passivation of negative electrodes in Na-ion cells. As was shown by Komaba et al. ${ }^{26}$ the charge efficiency of hard carbon materials is strongly dependent on the chosen solvents. This may be related to a difference in the $\mathrm{Na}^{+}$-conducting properties of the protective layer formed in presence of sodium ions. Further investigations should be directed towards the electronic insulating character as well as the $\mathrm{Na}^{+}$conductivity of this layer when formed in different electrolytes.

\section{Conclusions}

Local electrochemical measurements performed in the feedback mode of the SECM were used to successfully determine the potential for the SEI formation on glassy carbon surfaces $(0.8 \mathrm{~V}$ vs. $\left.\mathrm{Li} / \mathrm{Li}^{+}\right)$. The insulating properties of the SEI were qualitatively evaluated when different potential ranges were applied to the glassy carbon electrode during cyclic voltammograms. The role of the $\mathrm{Li}^{+}$cations on the insulating nature of the SEI was investigated as well.

When the electrode polarization reached $3 \mathrm{~V} v s . \mathrm{Li} / \mathrm{Li}^{+}$the magnitude of the normalized feedback current corresponding to the degree of insulation of the formed layer changed negligibly. It appears that the partial decomposition/dissolution of 
the SEI has a negligible effect on the insulating behaviour of this layer.

When lithium ions in solutions were replaced by $\mathrm{TBA}^{+}$or $\mathrm{Na}^{+}$, the formation of an electronic insulating layer was detected as well. Thus, it can be concluded that lithium ions do not play a fundamental role for the formation of an insulating layer. However, the presence of lithium ions may have an impact on other SEI characteristics such as ionic conductivity and mechanical properties, which are however not accessible by the proposed SECM technique. In particular, further studies in different electrolytes containing sodium ions may clarify the insulating properties of the protection layer formed on hard carbons.

\section{Acknowledgements}

GZ and WS are grateful to the Helmholtz-Energie-Allianz "Stationäre elektrochemische Speicher und Wandler" (HA-E0002) and FLM is grateful to the BMBF in the framework of the project "Energiespeicher" (FKN 3EK3005) for financial support. The authors are grateful to the Cluster of Excellence RESOLV (EXC 1069) funded by the Deutsche Forschungsgemeinschaft for financial support.

\section{References}

1 P. Arora, J. Electrochem. Soc., 1998, 145, 3647.

2 K. Xu, Chem. Rev., 2004, 104, 4303.

3 P. Verma, P. Maire and P. Novák, Electrochim. Acta, 2010, 55, 6332.

4 D. Aurbach, J. Electrochem. Soc., 1996, 143, 3809.

5 D. Aurbach, K. Gamolsky, B. Markovsky, Y. Gofer, M. Schmidt and U. Heider, Electrochim. Acta, 2002, 47, 1423.

6 L. J. Hardwick, H. Buqa, M. Holzapfel, W. Scheifele, F. Krumeich and P. Novák, Electrochim. Acta, 2007, 52, 4884. 7 M. Dollé, S. Grugeon, B. Beaudoin, L. Dupont and J.-M. Tarascon, J. Power Sources, 2001, 97-98, 104.

8 F. Kong, R. Kostecki, G. Nadeau, X. Song, K. Zaghib, K. Kinoshita and F. McLarnon, J. Power Sources, 2001, 9798, 58 .
9 J.-C. Panitz, F. Joho and P. Novak, Appl. Spectrosc., 1999, 53, 1188.

10 F. La Mantia, F. Rosciano, N. Tran and P. Novák, J. Electrochem. Soc., 2009, 156, A823.

11 F. La Mantia and P. Novák, Electrochem. Solid-State Lett., 2008, 11, A84.

12 M. E. Spahr, T. Palladino, H. Wilhelm, A. Würsig, D. Goers, H. Buqa, M. Holzapfel and P. Novák, J. Electrochem. Soc., 2004, 151, A1383.

13 F. La Mantia, J. Vetter and P. Novák, Electrochim. Acta, 2008, 53, 4109.

14 M. D. Levi and D. Aurbach, J. Electroanal. Chem., 1997, 421, 79.

15 G. Zampardi, E. Ventosa, F. La Mantia and W. Schuhmann, Chem. Commun., 2013, 49, 9347.

16 R. Imhof and P. Novak, J. Electrochem. Soc., 1998, 145, 1081.

17 M. Tang and J. Newman, J. Electrochem. Soc., 2012, 159, A1922-A1927.

18 S. Kaymaksiz, M. Wachtler and M. Wohlfahrt-Mehrens, J. Power Sources, 2015, 273, 123.

19 S. Pérez-Villar, P. Lanz, H. Schneider and P. Novák, Electrochim. Acta, 2013, 106, 506.

20 G. Zampardi, E. Ventosa, F. La Mantia and W. Schuhmann, Electroanalysis, 2015, DOI: 10.1002/elan.201400613.

21 C. Kranz, M. Ludwig, H. E. Gaub and W. Schuhmann, Adv. Mater., 1995, 7, 38.

22 A. J. Bard, F. R. F. Fan, J. Kwak and O. Lev, Anal. Chem., 1989, 61, 132.

23 D. Aurbach, J. Electrochem. Soc., 1994, 141, L1.

$24 \mathrm{H}$. Bryngelsson, M. Stjerndahl, T. Gustafsson and K. Edström, J. Power Sources, 2007, 174, 970.

25 L. J. Hardwick, M. Hahn, P. Ruch, M. Holzapfel, W. Scheifele, H. Buqa, F. Krumeich, P. Novák and R. Kötz, Electrochim. Acta, 2006, 52, 675.

26 S. Komaba, W. Murata, T. Ishikawa, N. Yabuuchi, T. Ozeki, T. Nakayama, A. Ogata, K. Gotoh and K. Fujiwara, Adv. Funct. Mater., 2011, 21, 3859. 